University of Florida Levin College of Law

UF Law Scholarship Repository

2012

\title{
Antitrust, Innovation, and Product Design in Platform Markets: Microsoft and Intel
}

\author{
William H. Page \\ University of Florida Levin College of Law, page@law.ufl.edu \\ Seldon J. Childers
}

Follow this and additional works at: https://scholarship.law.ufl.edu/facultypub

Part of the Antitrust and Trade Regulation Commons

\section{Recommended Citation \\ William H. Page \& Seldon J. Childers, Antitrust, Innovation, and Product Design in Platform Markets: Microsoft and Intel, 78 Antitrust L.J. 363 (2012), available at http://scholarship.law.ufl.edu/facultypub/ 629}

This Article is brought to you for free and open access by the Faculty Scholarship at UF Law Scholarship Repository. It has been accepted for inclusion in UF Law Faculty Publications by an authorized administrator of UF Law Scholarship Repository. For more information, please contact kaleita@law.ufl.edu. 


\title{
ANTITRUST, INNOVATION, AND PRODUCT DESIGN IN PLATFORM MARKETS: MICROSOFT AND INTEL
}

\author{
William H. Page \\ SELdON J. ChILdERS*
}

The Antitrust Division's Microsoft case' and the Federal Trade Commission's Intel case ${ }^{2}$ both rested on claims that antitrust intervention was necessary to preserve innovation in technological platforms at the heart of the personal computer. ${ }^{3}$ Yet those very platforms support markets that have long been among the most innovative in the economy. Intel's market in particular is the subject of Moore's Law, the most famous expression of the speed and consistency of innovation in the world of high technology. ${ }^{4}$ The innovative-

* Marshall M. Criser Eminent Scholar, University of Florida Levin College of Law; and Member of the Florida Bar, respectively. For helpful comments, we thank Annabelle Gawer, Joseph Kattan, and the participants at the Antitrust and the Wider Economy conference at the University of Michigan, October 2010.

I See United States v. Microsoft Corp., 253 F.3d 34, 49 (D.C. Cir. 2001) (D.C. Circuit 200I). Because so many opinions in the Microsoft litigation have the same name, the customary numbering of opinions by Roman numeral for citation (e.g., Microsoft $V$ ) conveys no information. Consequently, we adopt the citation strategy of William H. Page \& John E. Lopatka, The Microsoft Case: Antitrust, High Technology, and Consumer Welfare 203-42 (2007), which identifies the opinion by the court and year. The D.C. Circuit's pivotal 2001 opinion, for example, will be cited as D.C. Circuit 2001, 253 F.3d at

2 Complaint, Intel Corp., FTC Docket No. 9341 (Dec. 16, 2009) [hereinafter Intel Complaint], available at http://www.ftc.gov/os/adjpro/d9341/091216intelcmpt.pdf; Decision and Order, Intel Corp., FTC Docket No. 9341 (Oct. 29, 2010) [hereinafter Intel Order], available at http://www.ftc.gov/os/adjpro/d9341/101102inteldo.pdf. This order modifies, after the public comment period, a proposed order published on August 4, 2010.

${ }^{3}$ The role of antitrust in fostering (or not impeding) innovation has long preoccupied antitrust scholars. See, e.g., Jonathan B. Baker, Beyond Schumpeter v. Arrow: How Antitrust Fosters Innovation, 74 ANTITRust L.J. 575 (2007); Sean P. Gates, Standards, Innovation, and Antitrust: Integrating Innovation Concerns into the Analysis of Collaborative Standard Setting, 47 EMORY L.J. 583 (1998); John E. Lopatka \& William H. Page, Monopolization, Innovation, and Consumer Welfare, 69 Geo. WASH. L. Rev. 367 (2001); Daniel F. Spulber, Unlocking Technology: Antitrust and Innovation, 4 J. COMPETITION L. \& ECON. 915 (2008).

${ }^{4}$ Moore's Law, coined in 1965 by Gordon Moore (who went on to co-found Intel), predicts that the number of transistors on chips would double every eighteen months to two years. The prediction has proven remarkably accurate. See John Markoff, Advances Offer Path to Further 
ness of the markets raised the stakes for antitrust enforcers and courts, because injudicious intervention might well have jeopardized the very innovation that antitrust seeks to promote. In this article, we examine how Microsoft resolved these tensions and show how the experience in Microsoft informed the allegations and the disposition of Intel. We hope this exercise will help guide future applications of antitrust standards to high-technology platforms. $^{5}$

Microsoft and Intel were closely related in fact and law. The platforms at issue, one software, one hardware, are complementary elements of a larger platform: the Wintel standard, which combines some version of the Microsoft Windows operating system with the proprietary architecture of the x86 Intel central processing unit (CPU). ${ }^{6}$ Both Microsoft and Intel have had long runs as leaders of their respective markets, because of both innovation and entry barriers-closely related characteristics of most platform markets. The government's theories of monopolization in the two cases were also similar in important respects. In each case, a government plaintiff alleged that a dominant platform vendor illegally maintained a lawfully acquired monopoly in its home platform market-operating systems in Microsoft and CPUs in Intel. ${ }^{7}$ In each case, the government alleged that the defendant attempted to monopolize the market for a critical complementary product-browsers in Microsoft and graphics processing units or GPUs in Intel-in an effort to skew the direction of innovation to the advantage of its own entry in the complementary product market. ${ }^{8}$ In each case, the platform owner allegedly used various practices, including product design, to prevent a rival's version of the complement from becoming, by a process of innovation, a competing platform for other complements. At the remedy stage in Intel, the FTC used the term "predatory innova-

Shrink Computer Chips, N.Y. TIMES, Aug. 30, 2010, available at http://www.nytimes.com/2010/ $08 / 31 /$ science/31 compute.html?_r $=1 \& s c p=2 \& s q=\% 22$ moore $\% 27 \mathrm{~s} \% 201$ aw $\% 22 \& \mathrm{st}=\mathrm{cse}$. For a fascinating photoessay of the development of chips, see Kristina Grifantini, Moore's Law, TeCH. REv., Jan. 1, 2009, at 30.

${ }^{5}$ See, e.g., Geoffrey A. Manne \& Joshua D. Wright, Google and the Limits of Antitrust: The Case Against the Case Against Google, 34 Harv. J.L. \& Pub. Pol'y 171 (2011).

${ }^{6}$ For analysis of the incentives facing Microsoft and Intel in their unique relationship, see Ramon Casadesus-Masanell \& David B. Yoffie, Wintel: Cooperation and Conflict, 53 MgmT. Scr. 584 (2007); David B. Yoffie \& Mary Kwak, With Friends Like These: The Art of Managing Complementors, HARv. Bus. REv., Sept. 2006, at 89, 93-94 (2006). For potential challenges to the relationship, see Nick Wingfield, Microsoft Faces the Post-PC World, WaLl St. J., Aug. 15, 2011; The End of Wintel, Economist, July 31, 2010, at 53.

${ }^{7}$ D.C. Circuit 2001, 253 F.3d at 50-80; Intel Complaint, supra note 2, II 47. See John Graubert \& Jesse Gurman, The FTC/Intel Settlement: One Step Forward, One Step Back?, ANTI TRUST, Spring 2011, at 8, 11 (noting that the FTC's case in Intel "most resembled the Department of Justice's long-running litigation with Microsoft").

${ }^{8}$ D.C. Circuit 2001, 253 F.3d at 80-84; Intel Complaint, supra note 2, II 26. 
tion" to describe some of the design measures that allegedly disadvantaged Intel's rivals or might do so in the future. ${ }^{9}$

One important set of allegations in Intel went beyond Microsoft-claims that Intel excluded smaller rival CPU manufacturers AMD and Via by, for example, imposing contractual restrictions on computer manufacturers (OEMs). ${ }^{10}$ By contrast, none of Microsoft's challenged actions was aimed a rival producer of operating systems; its only targets were producers of socalled middleware, applications software that threatened to become rivals of Microsoft in a future market for software platforms. In this essay, we will limit our focus to the GPU allegations in Intel, those that most closely parallel the theory in Microsoft and most clearly raise the antitrust issues in the platform owner's relationship with complementors. ${ }^{11}$ In particular, we will analyze the parallel claims that Microsoft and Intel each used its control over the design of a dominant platform to prevent a complementary product from becoming a better substitute for the platform.

In Part I of this essay, we will describe some of the characteristics of platform markets and how innovation often occurs in them. In Part II, we will consider what antitrust standards should apply in markets like these, especially to issues involving product design. In Part III, we examine issues of market definition, liability, and remedies. For each of these sets of issues, we compare how the courts in Microsoft accounted for the issue of innovation in considering questions of product design and interoperability and compare that experience with the FTC's treatment of similar issues in its complaint and consent order in Intel.

\section{PLATFORMS AND INNOVATION}

A court considering a dominant firm's actions should place them alongside practices that are normal for firms in the market and thus presumably efficient. ${ }^{12}$ In this Part, we highlight some of the leading characteristics of the

\footnotetext{
${ }^{9}$ Analysis of Proposed Consent Order to Aid Public Comment at 13, Intel Corp., FTC Docket No. 9341 (Aug. 4, 2010) [hereinafter Analysis of Consent Order], available at http:// www.ftc.gov/os/adjpro/d9341/100804intelanal.pdf. The term had been in use long before the settlement. See, e.g, Joseph Gregory Sidak, Debunking Predatory Innovation, 83 Colum. L. REv. 1121 (1983).

10 Intel Complaint, supra note 2, III 5-7.

1 The term complementor was first used in AdAM M. BRandendurger \& BarRY J. NALEBUfF, Co-OPETITION 18 (1996) (suggesting that you are a complementor if "customers value your product more when they have the other [firm's] product than when they have your product alone").

12 Alan J. Meese, Monopolization, Exclusion, and the Theory of the Firm, 89 MinN. L. Rev. 743,793 (2005) (observing that "courts have implemented [S]ection 2's ban on monopolization by drawing a distinction between 'normal' competitive practices, on the one hand, and 'undue' or 'unreasonable' restrictions, on the other").
} 
kinds of markets at issue in Microsoft and Intel. In high-technology markets, including the markets for personal computers, firms often depend on both software and hardware platforms to develop their products. ${ }^{13}$ A software platform provides application programming interfaces, or APIs, that give developers access to standard functionality they can use to build advanced applications. In Windows, for example, the API provides file systems, a user interface, dialog boxes, device drivers, and networking, among many other services. ${ }^{14}$ APIs thus greatly reduce the costs of creating new products because developers only need to create the distinctive functionality that their own product delivers. ${ }^{15}$ The number and popularity of the applications that run on Windows enhance the value of the platform. Consequently, Microsoft offers extensive support (in over fifty languages) to a network of developers to create advanced applications to run on Windows. ${ }^{16}$

A hardware platform provides the physical architecture necessary for software and peripheral hardware devices to run and provide functionality. Intel produces microprocessors (central processing units, or CPUs) and related processors, chipsets, motherboards, and interfaces. The CPU of a personal computer, together with the operating system and chipset, manages all the other chips and resources in response to user commands. ${ }^{17}$ It keeps track of time and, again with the chipset, manages the demands of other devices for system resources ${ }^{18}$ and does much of the computing necessary to carry out software applications. ${ }^{19}$ Because of the innovative efforts of Intel and its ri-

${ }^{13}$ See, e.g., Platforms, Markets and Innovation (Annabelle Gawer ed., 2010); ANnabelle Gawer \& Michael A. Cusumano, Platform Leadership: How Intel, Microsoft, and Cisco Drive Industry Innovation (2002); David S. Evans, Andrei Hagiu \& Richard Schmalensee, Invisible Engines: How Software Platforms Drive Innovation and TRANSFORM INDUSTRIES (2006).

${ }^{14}$ See Overview of the Windows API, http://msdn.microsoft.com/en-us/library/Aa383723.

${ }^{15}$ David S. Evans \& Richard Schmalensee, Markets with Two-Sided Platforms, in 1 IssuEs IN COMPETITION LAw AND POlicy 667, 673 (ABA Section of Antitrust Law 2008) (observing that, by "reducing duplicative costs," APIs "increase ... the supply of applications for the platform [and] the value of the software platform to end users" and generate "positive feedback effects to application developers").

${ }^{16}$ See the Website of the Microsoft Developer Network, http://msdn.microsoft.com/en-us/default.aspx.

${ }^{17}$ For a more complete description of the CPU's role and its interaction with other internal components of the PC, see William Stallings, Computer Organization and Architecture: Designing for Performance, ch. 3 (2010). The CPU works closely with the operating system to manage sharing time between various internal components through the use of "interrupts."

18 The FTC's pleadings and documents, and the consent decree (and many other unrelated sources), describe the CPU as "the brains" of the computer. Intel Complaint, supra note 2, $\mathbb{3 3}$. The authors do not believe this is a particularly useful metaphor. Personal computers do not "think." However it is apt to the extent that the computer cannot function without a CPU.

${ }^{19}$ Our description of the CPU's functionality is necessarily simplified for this article's purposes. For a more complete explanation of how the CPU actually works, see STALLINGS, supra note 17, at 432-79 (Chapter 12: "Processor Structure and Function"). 
vals, summarized colloquially by Moore's Law, the speed of these processors continuously increases. This "law" carries with it a business imperative: to sell new, faster chips, Intel must ensure that developers and end-users need them. ${ }^{20}$ Intel therefore must promote innovation in hardware and software that spurs demand for its chips. ${ }^{21}$

Hardware and software platforms are multi-sided, placing the platform owner in the position of negotiating with (and mediating among) actors on all sides of the market. ${ }^{22}$ Microsoft, for example, must deal with applications developers that create the complementary products that give Windows much of its value; original equipment manufacturers, or OEMs, who install Windows and applications on new computers; ${ }^{23}$ hardware manufacturers whose products are controlled by drivers in Windows APIs; and end-users.

Intel, similarly, has aggressively asserted its position as developer of the hardware architecture at the heart of the modern PC. It provides software firms with business and technical information, including tools and code, they need to create new products that take advantage of the processing speeds of new generations of processors. ${ }^{24}$ They also provide interfaces or "buses" that allow other hardware developers to connect their products to the Intel CPU and chipset. The bus is significant because it must provide standardized, predictable interfaces between the CPU and memory, printers, keyboards, mice, peripherals, and the monitor. ${ }^{25}$

Particularly important in the FTC's Intel case is the PCI Express (or PCIe) bus, a series of electrical switches and expansion slots that connect the CPU to third-party chips and resources inside the computer using an industry-standard

${ }^{20}$ GAWER \& CuSumano, supra note 13 , at 17.

21 Microsoft does not face such a powerful imperative because it can sell products to its installed base. It too, however, must upgrade its platform regularly and induce innovation by complementors. See Yoffie \& Kwak, supra note 6, at 93.

22 David S. Evans, The Antitrust Economics of Multi-Sided Platform Markets, 20 YALE J. ON REG. 325, 328 (2003); see also Marc Rysman, The Economics of Two-Sided Markets, $23 \mathrm{~J}$. ECON. PersP., Summer 2009, at 125 (surveying the economic literature on two-sided markets).

${ }^{23} \mathrm{Microsoft}$, for example, sells most copies of Windows to OEMs to install on new computers. Because of the importance of this avenue of distribution, Microsoft has an interest in how its product and other complementary products are presented on the computer desktop. One of the issues in Microsoft was whether Microsoft or the OEM was a better steward of the public interest in deciding which applications appeared on the desktop. See also Jonathan M. Barnett, The Host's Dilemma: Strategic Forfeiture in Platform Markets for Informational Goods, 124 HARv. L. REv. 1861, 1872 (2011).

${ }^{24}$ See Intel Software Partner Program, INTEL. CORP., http://software.intel.com/partner/home? locale=en-US.

${ }^{25}$ See Stallings, supra note 17, ch. 3 (explaining the relationship between computer functions and interconnection devices); Gary B. Shelly \& Misty E. VermaAt, Discovering ComPuters 2010: Living in a Digital World 237-38 (2010) (describing the function of a computer bus, and defining the "expansion [type] bus" including PCIe). 
interface. ${ }^{26}$ Intel designed the original version the PCI bus as a layer that would allow it to redesign its processors repeatedly without affecting interoperability. ${ }^{27}$ Scores of manufacturers of expansions and add-ons rely on the PCle bus to connect to the CPU. ${ }^{28}$ The most important of these, for purposes of the Intel litigation, is the graphics processing unit, or GPU, which shares with the CPU the task of meeting the processing demands of software applications.

Chipsets are groups of related chips installed on the computer's motherboard that work with a CPU and a given bus standard to control computer functions. ${ }^{29}$ The CPU relies on the various chips in the chipsets for delegating specific tasks. For example, in certain Intel computers, the Southbridge chipset connects the CPU to various interfaces, like USB and PCIe sockets. AMD and Intel make a variety of pre-configured chipsets. ${ }^{30}$

The Wintel platform thus forms a durable yet constantly evolving base for an immense ecosystem of complementary products and related services, all aimed at providing functionality to end-users, whether consumers or enterprises. As scholars have recently observed, in markets like these, "contracting for innovation" replaces vertical integration for many functions:

[T] he performance of the product depends on the performance of a series of independently produced and rapidly developing subsystems . . . . The performance of each of these subsystems depends correlatively on the performance of the others, as transmitted through the architecture-the platform--linking them all.

In each case, the platform owner ... knows that it could not possibly produce all or even most of the components or applications whose interplay creates the platform. In particular, the producer could not develop or sustain the capacity for cutting-edge innovation in all the necessary areas for the various components. As a result, collaboration with groups of key technology suppliers, involving continuing mutual adjustment and exchange of quintessentially proprietary knowledge, becomes the norm. ${ }^{31}$

As with other platforms, the Windows system must compete with other platforms with systems of developers and OEMs. To compete effectively, a platform must evolve in response to consumer demand for greater speed and functionality. As we have seen, Microsoft and Intel must assure interoper-

\footnotetext{
26 See SHELLY ET AL., supra note 25, at 238.

${ }^{27}$ Gawer \& Cusumano, supra note 13 , at 31 .

28 See Stallings, supra note 17 , at 95.

29 See Aries PC Maintenance and Repair: Hardware (Teacher's Edition), at 145-46 (4th ed. 2007).

30 See id. at 146.

${ }^{31}$ Ronald J. Gilson, Charles F. Sabel \& Robert E. Scott, Contracting for Innovation: Vertical Disintegration and Interfirm Collaboration, 109 Colum. L. REv. 431, 440 (2009).
} 
ability through their interfaces and protocols, and must foster innovation by their systems of developers.

Thus, what might be called the "normal science" of innovation within a platform occurs in enhancing the functionality of complementary products. ${ }^{32}$ The platform provider facilitates this innovation by providing applications programming interfaces and other services like software development kits and technological support. The "revolutionary science" of innovation occurs when firms challenge the position of the platform itself. Competition among incompatible platforms is characterized by indirect network effects, which place a premium on building usage share, because the addition of new users makes the system more attractive to developers and the efforts of new developers in turn make the system more valuable to still more users. ${ }^{33}$ Firms in this phase of platform rivalry engage in aggressive forms of competition like giving products and services away to buyers on one or more sides of the market. ${ }^{34}$ In the familiar story, after a period of intense competition between rival incompatible platforms, the market may tip toward one dominant standard. ${ }^{35}$ Other platforms may persist, however, because indirect network effects may be exhausted once the number of users reaches a certain level. Tipping, moreover, is not forever. In some markets, new systems leapfrog old ones again and again. ${ }^{36}$ New technologies may displace the entire market. Consequently, even markets that have tipped in the initial stage may remain intensely competitive as newer products threaten to supplant the incumbent platform.

In Microsoft, the government's case rested on the existence of an "applications barrier to entry" consisting of network effects. ${ }^{37}$ The vast array of applications for Windows made it attractive for computer users to choose the Windows standard rather than another, and the greater number of users spurred developers to write programs for that standard as well. In Intel, the FTC alleged startup costs, IP rights, and "product reputation and compatibility" as barriers, but conspicuously omitted any allegation of network effects. ${ }^{38}$

\footnotetext{
32 Cf. Thomas S. Kuhn, The Structure of Scientific Revolutions 35-42 (3d ed. 1996) (describing the process of normal research testing the predictions of a scientific paradigm).

${ }^{33}$ Evans \& Schmalensee, supra note 15, at 678; Michael L. Katz \& Carl Shapiro, Systems Competition and Network Effects, J. ECON Persp., Spring 1994, at 93, 94.

${ }^{34}$ Katz \& Shapiro, supra note 33, at 107; see also Evans, supra note 22, at 367-70; Mark A. Lemley, Antitrust and the Internet Standardization Problem, 28 ConN. L. Rev. 1041, 1074-75 (1996).

${ }^{35}$ Katz \& Shapiro, supra note 33, at 107.

${ }^{36}$ Barnett, supra note 23, at 1877-78 (describing "precarious" position of platform owner); Evans, supra note 22 , at 365 (describing platform competition in the video game market).

${ }^{37}$ D.C. Circuit 2001,253 F.3d at 55-56. The court identified no other barriers to entry into the OS market.

${ }^{38}$ Over a decade ago, in an earlier case against Intel, the FTC did allege that network effects protected Intel's monopoly. Complaint, Intel Corp., FTC Docket No. 9288, at 3, II 10 (June 8, 1998), available at http://www.ftc.gov/os/1998/06/intelcmp.pdf (alleging that network effects
} 
Nevertheless, given the relationship between their products, Intel and Microsoft both benefit from similar indirect network effects.

The incentives of the platform vendor are generally, but not entirely, aligned with the consumer interest in its dealings with developers in the process of normal innovation. ${ }^{39}$ Introduction of new complements, which can create new markets and foster competition within markets built on the platform, spurs demand for the platform and provides more and better products to consumers. As we have already shown, platform providers lead innovative efforts and catalyze innovation by providing necessary interfaces, development kits, and information about demand. ${ }^{40}$ The platform owner thus stands to profit by the innovative efforts of applications developers that provide services consumers want without impairing the integrity of the platform. If the platform owner refuses to approve an application, it is probably (though not necessarily) because the application has some shortcoming that undermines the system. Apple, for example, said that it sometimes rejected applications for the iPhone because its sole carrier at the time, AT\&T, "expressed concerns regarding network efficiency and potential network congestion." ${ }^{41}$ Even in that case, Apple later relaxed its guidelines for developers in response to competition from phones running, for example, Google's Android operating system..$^{42}$

enabled Intel to win "commitments from many computer manufacturers and software vendors to build computers and write software for Intel's new 64-bit Merced microprocessor, even though the product will not be available for nearly two years") For discussion of that case, see Randal C. Picker, Regulating Network Industries: A Look at Intel, 23 HaRv. J.L. \& PUB. PoL'y 159 (1999).

${ }^{39}$ See Joseph Farrell \& Philip J. Weiser, Modularity, Vertical Integration, and Open Access Policies: Towards a Convergence of Antitrust and Regulation in the Internet Age, 17 HARV. J.L. \& TECH. 85, 105-19 (2003) (describing the limits of the platform owner's incentives to "internalize complementary efficiencies"); Geoffrey Parker \& Marshall W. Van Alstyne, Innovation, Openness, and Platform Control (Jan. 31, 2012), available at http://papers.ssm.com/sol3/papers .cfm?abstract_id=1079712; Pamela Samuelson, Are Patents on Interfaces Impeding Interoperability?, 93 MinN. L. REv. 1943, 1951 (2009).

40 David S. Evans, How Catalysts Ignite: The Economics of Platform-Based Start-Ups, in Platforms, Markets and InNovation, supra note 13, at 99.

${ }^{41}$ Erica Ogg, Apple Sheds Light on App Store Approval Process, CNET News.com (Aug. 21, 2009), http://news.cnet.com/8301-13579_3-10315328-37.html. The task of reviewing applications for approval is formidable:

Apple says it receives 8,500 new applications and updates to existing ones every week. There are 40 people responsible for reviewing every application submitted and each app gets reviewed by two people. Eighty percent are approved as submitted with no changes necessary, and 95 percent of applications are approved in two weeks or less. In total, since the App Store was opened last year, Apple says it has evaluated 200,000 Id. apps and updates.

42 Jenna Wortham, Apple Gives App Developers Its Review Guidelines, N.Y. Tumes, Sept. 9, 2010 (reporting industry analysts interpreted the new guidelines as "a sign that Apple was growing increasingly aware of competition in the smartphone market, and was trying to be friendlier to the developers whose applications have helped drive the success of its products"). But $c f$. Neil McAllister, Apple Tightens Its Grip on Developers with Mac App Store, INFoWorLd (Oct. 28, 
Thus far, we have focused on the role of the platform owner in fostering innovation by complementors. But, in some instances, the platform owner may choose to compete with its complementors or to displace them by adding its own functionality to the platform itself..$^{43}$ For example, if the complementary product market is monopolized, the platform owner may enter it to eliminate inefficient double marginalization. ${ }^{44}$ Or the platform owner may believe that it can provide a better or less expensive complement than those currently available. One study found that platform owners are more likely to integrate into "connector" markets, which are "functionally located between the platform and the applications" in a "stack of complementary markets," 45 because they define the larger platform's architecture and interface. For example, after Intel developed the first PCI bus in 1994, exponentially increasing the speed of connections within the PC, it decided that other chipset suppliers were lagging in manufacturing and distribution of the necessary technology and took that task on itself. ${ }^{46}$ Other connector markets that Intel has entered are motherboards and chipsets, including chipsets with integrated GPUs.

The challenge for the platform owner is to produce a platform and complements that create the fastest and most capable overall platform without deterring innovation by rival manufacturers of complements, who fear being wholly dependent on a competitor. ${ }^{47}$ Intel, for example, created internal divisions as separate profit centers with the conflicting missions of entering markets and subsidizing entry in the same markets by others, mainly by

2010) (observing that "while desktop applications are both more complex and costlier to produce than smartphone apps, Apple seems to want to hold developers to the same terms and standards for both, even as it competes for the same markets with its own software"), http:// www.infoworld.com/d/developer-world/apple-tightens-its-grip-developers-mac-app-store-319.

${ }^{43}$ See Annabelle Gawer \& Rebecca Henderson, Platform Owner Entry and Innovation in Complementary Markets: Evidence from Intel, 16 J. ECON. \& MGMT. STRATEgy 1, 2 (2007) ("[A]lthough some models suggest that entry in complementary markets is always optimal for a platform owner, others suggest that in some circumstances a platform owner's ability to commit not to enter complementary markets may be important to preserving complementors' incentives to innovate.").

44 Double marginalization occurs when "separate complementary monopolies, each imposing a monopoly markup, wind up with a final product price that exceeds the overall monopoly price." Farrell \&Weiser, supra, note 39, at 98. See also Christopher S. Yoo, Vertical Integration and Media Regulation in the New Economy, 19 YALE J. ON REG. 171, 261 (2002) (noting that "[v]ertical integration ... allow[s] the combined entity to ignore the appropriate transfer price and instead focus solely on the price charged for the final delivery of the service . . . [thus allowing] the entity to eliminate the markup charged by the content provider and price the final good closer to the welfare-maximizing level").

${ }^{45}$ Gawer \& Henderson, supra note 43, at 10; see also Thomas R. Eisenmann, Geoffrey Parker \& Marshall Van Alstyne, Opening Platforms: How, When and Why?, in Platforms, Markets AND INNOVATION, supra note 13, at 131, 146-49.

46 Gawer \& Henderson, supra note 43, at 12.

$47 \mathrm{ld}$. at $6-7$; Barnett, supra note 23 , at $1879-81$ (describing the dilemma facing platform owners to persuade potential adopters that it will not later exploit switching costs to expropriate value from them, if they are successful). 
development assistance and sharing of intellectual property. ${ }^{48}$ Twitter, according to some reports, considered building the functionality of some third-party applications into the Twitter platform. Twitter's leading investor explained this move by distinguishing applications that "fill holes" in a platform (e.g., photo sharing) from "killer apps" that "create something entirely new on top" of the platform (e.g., social gaming): "Twitter really should have had [the hole-filling applications] when it launched or it should have built those services right into the Twitter experience." 49 Developers, he suggested, should focus on the killer apps and leave the hole-filling to Twitter.

But which applications fill holes and which are killer add-ons is not something that can be decided for all time at any moment. As one industry analyst has observed, a platform can be a utility for other firms' applications, a suite of the platform owner's applications, or anything in between. The platform vendor must consider and reconsider where it wants to be on the continuum:

If Twitter were to have continued its role as utility, it is hard to see how it could have generated an acceptable return for its investors (and sustained itself over the long run). If, conversely, it decided to go head-to-head with the developer community on all fronts, it would have made a lot of money in the short run but stifled innovation that would have damaged its long-run prospects for value maximization. However, it has chosen likely the most difficult but most rewarding path, that of providing the functionality of a utility while also owning pieces of the application value stack. This has created a delicate balancing act with the developer community that will take time to play out, and will require far better communication with the community than it has had to date. But when the dust settles Twitter will control the most valuable engine of monetization-mobile advertising-while enabling others to earn significant profits from their own applications. This potential for profits will continue to draw in elements of the developer community most consistent with the white space Twitter has left open, driving innovation that will further attract new users and potential ad dollars for the mother ship. Near term pain and discomfort for long-term gain. ${ }^{50}$

A platform owner's decision to add new functionality to the platform itself will ordinarily depend, as the Coase theory of the firm suggests, ${ }^{51}$ on whether the owner can perform that function better or at lower cost internally than by contracting with application developers. ${ }^{52}$ Both platform vendors and develop-

\footnotetext{
${ }^{48}$ Gawer \& Henderson, supra note 43, at 18-21.

49 Fred Wilson, The Twitter Platform's Inflection Point, AVC: Musings of a VC in NY (Apr. 7, 2010), http://www.avc.com/a_vc/2010/04/the-twitter-platform.html.

${ }^{50}$ Roger Ehrenberg, Twitter: Optimizing Long-term Value, Information Arbitrage (Apr. 13, 2010), http://www.informationarbitrage.com/2010/04/twitter-optimizing-longterm-value. html.

${ }^{51}$ Ronald H. Coase, The Nature of the Firm, 4 Economica 386, 392 (1937).

52 Cf. David S. Evans \& Michael A. Salinger, The Role of Cost in Determining When Firms offer Bundles, 56 J. INDus. ECON. 143 (2008) (arguing that, where there are high fixed costs,
} 
ers have incentives to enhance the attractiveness of the system. The network effects of the larger system operate to the benefit of both the platform owner and developers by creating greater incentives for the users and new developers to choose their system over others. Consequently, the platform owner's choice to integrate functionality will usually have efficiency justifications.

If a platform owner's move supplants a complementor or limits a complementor's interoperability, ${ }^{53}$ the disfavored complementor may suspect that the platform owner's action is predatory, especially if the complementor aspires to become a platform in its own right. ${ }^{54}$ These concerns cannot be rejected based on the considerations we have outlined in this section, because bundling and denials of interoperation may be inefficient. ${ }^{55}$ The platform owner may have an incentive to use its position as a gatekeeper to thwart the development of a complementor's product that competes with one of the platform owner's complements or that threatens to become a rival platform. As Philip Weiser has observed, platform owners are in a position to reduce social welfare by deterring innovation that "facilitat[es] competition in the platform market itself or undermin[es] the ability of the rival platform provider to engage in price discrimination." 56 This concern underlies the government cases in both Microsoft and Intel and is the basis for their intervention in both platform owners' design choices.

bundling may be an efficient way of providing goods to consumers with various tastes, even if few want both components).

53 See, e.g., Chun-Hui Miao, Limiting Compatibility in Two-Sided Markets, 8 Rev. Network ECON. 346 (2009) (showing that, in a two-sided market, a monopolist may have an incentive to limit compatibility with complementary products in order to extract surplus from users on both sides of the market).

${ }^{54}$ Dennis W. Carlton \& Michael Waldman, The Strategic Use of Tying to Preserve and Create Market Power in Evolving Industries, 33 RAND J. ECON. 194 (2002) (arguing that tying of a complementary product in one time period can forestall entry by a rival producer of the complementary product into its monopoly market in a later time period); see also Joseph Farrell \& Michael L. Katz, Innovation, Rent Extraction, and Integration in Systems Markets, 48 J. INDus. ECON. 413, 430 (2000) (showing that innovation and forward integration may be "inefficient to the extent that they are driven by the pecuniary gains from lower prices in the complement rather than by internalization of real externalities from innovation"); Barry Nalebuff, Bundling as an Entry Barrier, Q.J. ECoN. 159 (2004) (arguing that a monopolist of complementary goods can deter entry in both markets by bundling); Martin Peitz, Bundling May Blockade Entry, 26 INT'L J. INDUS. ORG. 41 (2006) (describing conditions under which bundling can prevent entry and reduce welfare).

55 Farrell \& Weiser, supra note 39, at 110-11 (describing the platform owner's incentive to limit potential competition); Gawer \& Henderson, supra note 43, at 4 (observing that "the literature exploring a monopolist's incentive to enter the market for complements is subtle and complex, and whether a monopolist will choose to enter complementary markets or as to whether such entry will enhance or reduce social welfare cannot be answered unequivocally").

56 Philip Weiser, Regulating Interoperability: Lessons from AT\&T, Microsoft, and Beyond, 76 ANTITRUST L.J. 271, 291-92 (2009). 


\section{PLATFORMS AND ANTITRUST}

In this section, we consider how antitrust standards for platform markets might foster innovation. The task is complicated because antitrust can best promote innovation by intervening in platform design decisions or by declining to intervene, depending upon the circumstances. ${ }^{57}$ Antitrust law has, for example, struggled to define the exceptions to the "right" of even dominant firms like leading platform owners to choose with whom they wish to deal. ${ }^{58}$ Aspen Skiing suggested that a dominant firm could not withdraw from a longstanding arrangement with a rival, if doing so harmed consumers. ${ }^{59}$ More recently, Trinko characterized the holding in Aspen as setting "the outer boundary" of an antitrust duty to deal. ${ }^{60}$ Nevertheless, "even the Trinko dictum will not erase the role for antitrust oversight of cooperation (or lack thereof) between rivals in network industries."61

The experience in Microsoft (including some cautionary lessons from the courts' missteps) provides a benchmark for later courts and agencies applying monopolization standards in platform markets, particularly on issues of product design and interoperability. It suggests how a court or agency should consider the special role of platforms in the process of innovation when it identifies monopoly power, evaluates exclusionary conduct, and shapes remedies. Intel provides a useful illustration of how well the lessons of Microsoft have been learned.

Both sides in Microsoft stood for innovation. The government argued that Microsoft's integration of its browser with Windows and its restrictive agreements with computer manufacturers (OEMs), among others, hampered innovation by preventing Netscape's browser and the Java technologies from

\footnotetext{
57 Herbert Hovenkamp, Restraints on Innovation, 29 CARdozo L. Rev. 247, 253 (2007) (observing that although "the social losses that result from innovation restraints are immense . . . identifying anticompetitive innovation restraints has proven to be very difficult and development of suitable remedies even more problematic").

58 See NYNEX Corp. v. Discon, Inc., 525 U.S. 128, 137 (1998) ("The freedom to switch suppliers lies close to the heart of the competitive process that the antitrust laws seek to encourage."); United States v. Colgate \& Co., 250 U.S. 300,-307 (1919).

${ }^{59}$ Aspen Skiing Co. v. Aspen Highlands Skiing Corp., 472 U.S. 585 (1985).

60 Verizon Commc'ns Inc. v. Law Offices of Curtis V. Trinko, LLP, 540 U.S. 398, 409 (2004).

${ }^{61}$ Weiser, supra note 56, at 273; see also John E. Lopatka \& William H. Page, Bargaining and Monopolization: In Search of the "Boundary of Section 2 Liability" Between Aspen and Trinko, 73 Antitrust L.J. 115 (2005); Howard A. Shelanski, Unilateral Refusals to Deal in Intellectual and Other Property, 76 ANTTTRust L.J. 369, 390-94 (2009) (arguing, based on an error-cost analysis, that a rule of per se legality for unilateral refusals to deal is unwarranted); Daniel F. Spulber \& Christopher S. Yoo, Mandating Access to Telecom and the Internet: The Hidden Side of Trinko, 107 Colum. L. Rev. 1822, 1900-01 (2007) (identifying the potential transaction costs and perverse effects on innovation from unduly broad mandates of platform access).
} 
evolving into a platform for software applications that could rival Windows. Microsoft responded that the enhancement of Windows by the integration of a critical new function like Web browsing was innovation itself and its dealings with OEMs, Internet Access Providers, and software developers were part and parcel of its role in promoting Windows platform for other firms' innovative efforts. The great challenge for the courts was to frame and to apply antitrust standards that could assess these narratives and impose remedies that would stop conduct that harmed innovation, but still permit conduct that was itself innovative.

Some have argued that antitrust should have little or no role in high-technology platform markets because the rate of innovation makes antitrust intervention unnecessary. ${ }^{62}$ Others argue, however, that the presence of network effects can make the consequences of the anticompetitive conduct more durable by giving the platform leader a dominant position. ${ }^{63}$ The D.C. Circuit in Microsoft sugested that "the economic consequences of network effects and technological dynamism act to offset one another, thereby making it difficult to formulate categorical antitrust rules absent a particularized analysis of a given market." 64 The court recognized that a platform's dominance "may be temporary, because innovation may alter the field altogether." 65 Competition in platform markets, in other words, often proceeds "sequentially" rather than "simultaneously." Nevertheless, even if the market is "uniquely dynamic in the long term," a dominant platform may have monopoly power in the short term, particularly if the platform owner can exploit its position to extend its dominance. ${ }^{66}$ The central position of the platform leader gives it unusual influence over the success or failure of complementors and rivals. Even if competition between platforms is for the market rather than within the market, the competition should still be subject to an appropriate level of antitrust scrutiny.

Courts confronted with antitrust claims in platform markets must, however, be aware of the forms the competition is likely to take and be ready to distinguish the malign from the benign, even where they look similar in outward appearance. Active competition in platform markets may look like predation

\footnotetext{
A25.

62 See, e.g., Virginia Postrel, What Really Scares Microsoft, N.Y. Times, Nov. 8, 1999, at

${ }^{63}$ Platform owners may also gain a measure of dominance if standards-setting organizations approve standards that include their intellectual property. For discussion of the complex issues involved in the application of antitrust standards to conduct before SSOs, see Salil K. Mehra, Paradise Is a Walled Garden? Trust, Antitrust, and User Dynamism, 18 Geo. Mason L. Rev. 889, 939-47 (2011).

${ }^{64}$ D.C. Circuit 2001,253 F.3d at 50 .

${ }^{65} \mathrm{Id}$. at 49.

${ }^{66} \mathrm{Id}$. at 57 . The same result holds even though the monopolist continues to innovate: "because innovation can increase an already dominant market share and further delay the emergence of competition, even monopolists have reason to invest in R\&D." Id.
} 
in other markets, as firms try to become (or to maintain) the market standard. ${ }^{67}$ Legitimate actions of a platform owner in improving its platform or protecting the platform's integrity may seem only to protect its dominant position from revolutionary innovative efforts of its complementors. For example, a platform owner's efforts to enhance its platform by design choices, including integration of new functionality into the platform, may harm complementors by reducing the price of that functionality (perhaps to zero) or by completely or partially excluding the complementor's product from the platform. ${ }^{68}$

The technological complexity of platform markets also makes it difficult for courts to identify and remedy anticompetitive actions, particularly design choices, in time to improve matters. The second district judge in Microsoft likened her task to "trying to shoe a galloping horse." 69 Mistaken applications of antitrust rules will be more costly in platform markets if they hinder innovation by the platform owner.

The D.C. Circuit acknowledged all of these concerns in framing its approach in Microsoft but did not shrink from examining Microsoft's conduct, even on issues of product design. Its monopolization standard required the plaintiff to prove that the practice harmed the "competitive process [in the market for operating systems] and thereby harmed consumers" rather than merely competitors. ${ }^{70}$ If the plaintiff carried this burden, the defendant was required to offer a procompetitive justification for its act, "a nonpretextual claim that its conduct is indeed a form of competition on the merits because it involves, for example, greater efficiency or enhanced consumer appeal." ${ }^{\prime 11}$ If the defendant established a plausible justification, the plaintiff was required either to rebut it or to show, in a rule-of-reason inquiry, that the anticompetitive harm outweighs it. ${ }^{72}$

The first two steps of the analysis disposed of all of the government's contentions: if the practice was not anticompetitive in a relevant sense, or if

\footnotetext{
${ }^{67}$ Lemley, supra note 34 , at 1074-75.

${ }^{68} \mathrm{Cf}$. Sang-Yong Tom Lee \& W. Wayne Fu, Software-Platform Integration, Incompatibility, and System-User Switching, 19 J. MEDIA ECON. 163, 190 (2006) (finding "a theoretical basis for the view that an integrated supplement-base company can indeed drive out its competitors by making its supplement subsidiary's product incompatible with or unavailable to users of a competing base").

${ }^{69}$ New York v. Microsoft Corp., 224 F. Supp. 2d 76, 184 (D.D.C. 2002) (D.D.C. States Remedy 2002), aff'd sub nom. Massachusetts v. Microsoft Corp., 373 F.3d 1199 (D.C. Cir. 2004) (D.C. Circuit 2004) ("Thus, although the remedy crafted by the Court is undoubtedly forwardlooking, it is beyond the capacity of this Court, counsel, or any witness, to craft a remedy in 2002, for antitrust violations which commenced in the mid-1990s, which will be appropriately tailored to the needs of a rapidly changing industry in 2012.").

${ }^{70}$ D.C. Circuit 2001,253 F.3d at 58-59.

${ }^{71}$ Id. at 59.

72 Id.
} 
Microsoft justified it by valid efficiency considerations, the practice was lawful; if it was anticompetitive and unjustified, it was unlawful. Crucially, the court did not require proof of anticompetitive effects in the usual sensehigher prices and lower output. At least in the unusual circumstances in Microsoft, ${ }^{73}$ it was sufficient to "infer causation when exclusionary conduct is aimed at producers of nascent competitive technologies" because "neither plaintiffs nor the court can confidently reconstruct a product's hypothetical technological development in a world absent the defendant's exclusionary conduct." "74 A monopolist should not be given "free reign to squash nascent, albeit unproven, competitors at will-particularly in industries marked by rapid technological advance and frequent paradigm shifts." 7 . Instead, it should be "made to suffer the uncertain consequences of its own undesirable conduct." 76

Thus, liability hinged on whether the conduct was "undesirable." What the court considered undesirable became clear as it addressed specific practices. In essence, a practice was undesirable if it hurt nascent rivals without obviously helping consumers. If the practice provided sufficiently obvious consumer benefits-for example, by providing a demonstrably better product or the same product at a lower price, either to end-users or complementors-then it was not anticompetitive at all, regardless of how seriously it hurt rivals. If the practice hurt Netscape or Java by limiting usage share while providing less obvious consumer benefits, the court might conclude that the practice was anticompetitive but would consider efficiency justifications. ${ }^{77}$ This approach ran the risk of costly false positives-error costs that might be harder to correct, especially in dynamic markets, than the false negatives that a more exact-

\footnotetext{
${ }^{73}$ One court has recently emphasized that the plaintiff must prove that "suppression of nascent threats . . had an actual adverse effect on competition in the relevant market." Princo Corp. v. ITC, 616 F.3d 1318, 1338 (Fed. Cir. 2010). That required the plaintiff to show that "there was a 'reasonable probability' that the [nascent] technology, if available for licensing, would have matured into a competitive force in the [relevant] market" and not merely a "speculative possibility that [the nascent technology] could have overcome the barriers to its technical feasibility and commercial success." Id.

${ }^{74}$ D.C. Circuit 2001, 253 F.3d at 79 (emphasis added).

${ }^{75} \mathrm{Id}$.

${ }^{76} \mathrm{ld}$. (quoting 3 Phillip E. Areeda \& Herbert Hovenkamp, Antitrust Law II 651c, at 78 (1996)).

77 Microsoft's license restrictions and design choices that hindered OEMs' flexibility in configuring new computers, including its removal of programs in Windows, were anticompetitive, on the theory that OEMs would only act to benefit consumers. Contracts and dealings with complementors that directly limited their ability to deal with rivals' products were potentially anticompetitive.

The court condemned various measures aimed at limiting the ability of other complementors to distribute Netscape's browser or Java. In each instance, the court found that the practices had no business justification and specifically rejected Microsoft's assertion that it had a legitimate business interest in keeping developers focused on the Windows API.
} 
ing standard of proof of anticompetitive effect might entail. ${ }^{78}$ Nevertheless, the court's approach did take seriously Microsoft's role as an innovator and a competitor. Moreover, it mitigated the potential overbreadth of the standard of liability by reintroducing the issue of causation in framing remedies, which we also address in the next Part.

The legal standards in Microsoft provide a basis for evaluating Intel. Although the settlement in Intel, by its nature, does not identify a guiding standard of liability, ${ }^{79}$ the parties negotiated it in the shadow of the standards that they expected the courts to apply. ${ }^{80}$ The parties probably expected Section 5 of the Federal Trade Commission Act standards to be similar to those applied in Microsoft under Section 2 of the Sherman Act. Thus, the FTC, in all likelihood, prepared to prove that Intel's conduct harmed the competitive process in the market for CPUs and thereby harmed consumers, not just its rivals. Intel undoubtedly prepared to show that its acts obviously provided consumer benefits by improving speed, functionality, and efficiency. The settlement reflects an accommodation of these concerns.

In its complaint, the FTC asserted (at least as a fallback position) that Section 5 might reach conduct that does not violate Section $2 .{ }^{81}$ But there is no reason to believe courts would agree, at least in this instance. ${ }^{82}$ One of us has argued elsewhere that Section 5 has no broader reach than Section 1 of the Sherman Act in regulating agreements in restraint of trade because antitrust policy considerations, not the statutory text, determine the content of Section

78 See William H. Page, Microsoft and the Limits of Antitrust, 6 J. Compention L. \& Econ. 33 (2010) (applying to the Microsoft case the error-cost framework of Frank H. Easterbrook, The Limits of Antitrust, 63 TEX. L. Rev. 1 (1984)).

79 Analysis of Consent Order, supra note 9, at 2 ("The prohibitions and standards utilized in the Proposed Consent Order do not necessarily reflect the applicable legal standards under the Sherman Act, Clayton Act, or the FTC Act; indeed, the legal standards applicable to some of these practices remain unsettled by the Supreme Court and the federal courts of appeal.").

${ }^{80} \mathrm{Cf}$. Robert H. Mnookin \& Lewis Kornhauser, Bargaining in the Shadow of the Law: The Case of Divorce, 88 YALE L.J. 950 (1979).

81 Intel Complaint, supra note 2, II 1 (emphasizing power to stop anticompetitive acts in their incipiency).

${ }^{82}$ One FTC Commissioner has argued that Section 5 reaches unilateral conduct not covered by Section 2. J. Thomas Rosch, The FTC's Section 5 Hearings: New Standards for Unilateral Conduct?, Remarks Before ABA Antitrust Section Spring Meeting (Mar. 25, 2009), available at http://www2.ftc.gov/speeches/rosch/090325abaspring.pdf. But Commissioner Rosch is careful to identify "unique circumstances" and "limiting principles" that justify any departure from Microsoft's standards for identifying exclusionary conduct. Id. at 5-6. He argued, for example, that N-Data's disavowal of an earlier commitment to license patents that a standards-setting body had adopted violated Section 5 even if it was not exclusionary under Section 2 . Consent Order, Negotiated Data Solutions, LLC, FTC Docket No. C-4234 (Sept. 23, 2008), available at http:// www.ftc.gov/opa/2008/09/nds.shtm. Intel did not involve a comparable official standards-setting context, possibly justifying a standard different from the one applied by the D.C. Circuit in Microsofi. 
1's requirement of concerted action. ${ }^{83}$ The same reasoning suggests that Section 5 has no broader reach than Section 2 of the Sherman Act in cases alleging monopolization by platform vendors. "Monopolization," from a purely lexical viewpoint, is no less inclusive than "unfair methods of competition." Given the breadth of the statutory terms, courts have necessarily defined their reach by reference to the error costs associated with intervention, not by their literal meanings, whatever those might be.

Consider the FTC's assertion in Intel that Section 5 extends to incipient ${ }^{84}$ and "synergistic" anticompetitive effects. The DOJ made similar allegations in Microsoft, but the court of appeals reversed as unsupported the district court's holding that Microsoft's entire course of conduct amounted to a violation separate from its individual acts. ${ }^{85}$ On the other hand, the court recognized that conduct could be unlawful even without proof that the conduct had presently reduced output or raised prices. There is no reason to think that the FTC is in a position to identify still more incipient anticompetitive effects with sufficient accuracy to justify the increased error costs of intervention.

The aftermath of the Microsoft case gives additional reason for caution in the application of a standard of incipiency. Important outcomes in the case hinged on predictions of the future course of technological change. The liability holding, for example, rested on the court's prediction that Netscape's browser could become a platform rival of Windows and thus lower the applications barrier to entry protecting the Windows monopoly. ${ }^{86}$ Microsoft and Netscape both bought into this prediction, at least early on, ${ }^{87}$ and the court of appeals accepted it as a basis for upholding liability for unjustified competitive harm to a nascent rival, even in the absence of traditional proof of that Microsoft had harmed competition. ${ }^{88}$ The protocol licensing requirement, which the parties included in the negotiated settlement, was aimed at ensuring

\footnotetext{
${ }^{83}$ William H. Page, The FTC's Procedural Advantage in Discovering Concerted Action, AN. TITRUST SourCE, Feb. 2009, at 1-2, http://www.abanet.org/antitrust/at-source/09/02/Feb09Page2-26f.pdf.

${ }^{84}$ Intel Complaint, supra note 2, II 1 (asserting that "where a respondent that has monopoly power engages in a course of conduct tending to cripple rivals or prevent would-be rivals from constraining its exercise of that power, and where such conduct cumulatively or individually has anticompetitive effects or has a tendency to lead to such effects, that course of conduct falls within the scope of Section 5") (emphasis added).

${ }^{85}$ D.C. Circuit 2001,253 F.3d at 78.

$86 \mathrm{Id}$. at 53.

${ }^{87}$ Bill Gates presented it in his "Internet Tidal Wave" memo. Memorandum from Bill Gates to Executive Staff and Direct Reports at Microsoft 4 (May 26, 1995) [hereinafter Internet Tidal Wave memo], available at http://www.justice.gov/atr/cases/ms_exhibits.htm (Exhibit 20). Netscape presented it in a White Paper urging government action against Microsoft. Gary Reback \& Susan Creighton, White Paper Regarding Recent Anticompetitive Conduct of Microsoft Corporation 48-51 (July 1996) (unpublished manuscript, on file with authors).

${ }^{88}$ D.C. Circuit 2001,253 F.3d at 79 (because "neither plaintiffs nor the court can confidently reconstruct a product's hypothetical technological development in a world absent the defendant's
} 
that server-based middleware would also become a platform rival. ${ }^{89}$ In neither case did technology develop as predicted. Windows faces growing competition, but it comes from other quarters, such as Web services, tablets, and handheld devices. ${ }^{90}$ There is some reason to think that the government misperceived the likely course of innovation in Intel also, as we explain more fully in the next Part. This experience that courts should scrutinize the competitors' and litigants' predictions of the competitive effects of platform design choices.

\section{APPLYING ANTITRUST STANDARDS IN PLATFORM MARKETS}

In Microsoft, the courts took account of the platform's central role in innovation in defining markets; identifying genuinely exclusionary conduct, including actions affecting product design and interoperability; and framing remedies. Those analyses help us interpret the complaint and the consent order in Intel.

\section{A. Market Definition}

The courts in Microsoft defined the relevant market as operating systems for Intel-compatible personal computers. The unique role of operating systems as platforms for the full-featured computer programs ruled out multitudes of other software platforms, like operating systems for handheld devices and "middleware"-applications with platform capabilities. "Consumers could not," the court found, "now abandon their operating systems and switch to middleware in response to a sustained price for Windows above the competitive level." 91

Paradoxically, however, the government's case rested on its contention that Microsoft injured competition in the market for operating systems by excluding two middleware products, Netscape's browser and Sun's Java. Netscape's browser, as Bill Gates himself observed, might "commoditize the underlying

exclusionary conduct" so Microsoft must "suffer the uncertain consequences of its own undesirable conduct").

${ }^{89}$ D.D.C. States Remedy 2002, 224 F. Supp. 2 d at 129 (observing that $\S$ III.E of the remedy keeps open "the new model of the "platform threat" ").

${ }_{90}$ See, e.g., Wingfield, supra note 6 . Web services, admittedly, are accessed generally through a browser or with browsing technology, but in almost all cases, any browser will do; browserspecific network effects do not exist, as the court in Microsoft itself recognized. D.C. Circuit 2001,253 F.3d at 84 ("Not only did plaintiffs fail to articulate a website barrier to entry theory in either their brief or at oral argument, they failed to point the court to evidence in the record that would support a finding that Microsoft would likely erect significant barriers to entry upon acquisition of a dominant market share."). Consequently, it was doubtful from the outset that Netscape could ever have evolved into a platform rival to Windows.

${ }^{91}$ D.C. Circuit 2001, 253 F.3d at 54. 
operating system"92 if it became a platform that would allow developers to write programs that would run on any operating system. By delaying innovation by Netscape and Java, the government argued, Microsoft hindered their development as a rival platform and preserved the "applications barrier to entry" or network effects shielding Windows' dominance of the market for operating systems. Microsoft argued that, if middleware products were victims, then middleware must be in the relevant market. But the court avoided this contradiction by classifying Netscape's browser and Java as nascent competitors-not presently in the market, but posing a sufficient threat to alter the platform market to Microsoft's disadvantage to warrant protection against Microsoft's depredations. ${ }^{93}$

Ostensibly applying the same criteria of market definition, however, the court held that the government had failed to establish the existence of a browser market, ${ }^{94}$ at least one sheltered by network effects. ${ }^{95}$ This finding not only meant that Microsoft had not attempted to monopolize a market for browsers, but also that Microsoft did not compete with Netscape in any defined market. Netscape's browser was a nascent competitor of Microsoft only in the speculative sense that it might compete with Microsoft in a market for platforms that might, through a process of innovation, exist in the future.

In Intel, the FTC alleged that the defendant had monopolized a set of markets for CPUs and attempted to monopolize a set of markets for GPUs. As in Microsoft, the contentions of anticompetitive effect depended on proof of the existence of these markets-something the FTC avoided by settling. On the surface, however, the connection between the alleged markets and the alleged anticompetitive effects are clearer in Intel than in Microsoft. First, Intel included allegations of harm to present smaller rivals (AMD and Via) in a market in which Intel has monopoly power (CPUs). Second, the competitive relationship between the platform market and the complementary good market (GPUs) has a long and informative history. We will focus here on the second of these competitive relationships.

The FTC alleged that Intel sought to hinder the development of rivals' GPUs. ${ }^{96}$ A GPU is special-purpose hardware that handles graphics calcula-

\footnotetext{
92 United States v. Microsoft Corp., 84 F. Supp. 2d 9, 29 (D.D.C. 1999), aff'd in part, rev'd in part, 253 F.3d 34 (D.C. Cir. 2001).

${ }^{93}$ D.C. Cir. 2001,253 F.3d at 54 (reasoning that "no contradiction exists" because "middleware's threat is only nascent" and Section 2 can reach products that are not "already well developed enough to serve as present substitutes").

${ }^{94} I d$. at 81-82. The government's failure in this respect was so complete that it was given no opportunity to prove the existence of a browser market on remand. Id.

$95 \mathrm{Id}$. at $82-84$.

96 The GPU is defined in the Consent Decree as: "one or more integrated circuit(s) that: (i) is the primary graphics processing unit in a Computer Product; (ii) is capable of performing real-
} 
tions much faster than the CPU, which must also manage the system. A discrete or dedicated GPU combines a graphics processor with dedicated memory and a cooling system into a unit that plugs into an expansion slot on the computer's motherboard. Most GPUs, however, are integrated with a chipset and depend on the system's memory and cooling system. These integrated GPUs, produced by Intel, AMD, and others, are less capable of performing the most advanced graphics functions but are sufficient for most users. Intel has a large and growing share in the GPU market but produces only integrated GPUs. NVidia and AMD's ATI subsidiary account for virtually all sales of dedicated or discrete GPUs. ${ }^{97}$ Hardware manufacturers typically sell systems preconfigured with an integrated graphics processor or a dedicated GPU, depending upon the user's preferences. High-end laptops may include both, allowing the user to select between the greater processing power of the dedicated GPU and the lower power usage of the integrated GPU.

According to the FTC, Nvidia and AMD had a lead in innovation in General Purpose GPUs (GP-GPUs), ${ }^{98}$ which threatened to take over more of the functions of the CPU and thereby to "marginalize Intel's long-standing CPUcentric, x86-based strategy."99 GP-GPUs provide certain non-graphics processing functions typically found in the CPU. Games and high-end mathematical and scientific applications can use the GP-GPU for certain kinds of non-graphics calculations, if they are programmed to do so. ${ }^{100}$ Moreover,

time graphics rendering tasks separate from that Computer Product's Relevant Microprocessor Product; (iii) does not provide the primary interface between the Computer System's Relevant Microprocessor Product and storage (including without limitation a hard disk drive); and (iv) does not provide the primary interface between the Computer System's Relevant Microprocessor Product and input devices (including without limitation a keyboard)." Intel Order, supra note 2, $\S \mathrm{I}$ I.EE.

${ }^{97}$ Cyril Kowaliski, GPU Sales Strong as AMD Gains Market Share, TECHREPORT.Com (Oct. 27, 2008), http://techreport.com/discussions.x/15778. AMD and Nvidia have defended claims that they fixed prices for their products. In re Graphics Processing Units Antitrust Litig., 253 F.R.D. 478 (N.D. Cal. 2008) (ruling on motions of various putative classes of plaintiffs for certification).

98 Intel Complaint, supra note 2, II 15 ('The GPU markets are highly concentrated and dominated by Intel. Intel currently lags behind its competitors in both quality and innovation for both discrete GPUs (GPUs used on separate graphics cards) and integrated GPUs (GPUs integrated into computer chipsets). Intel's market share in the GPU markets is in excess of 50 percent.").

99 Id. TI 16 (emphasis added); see also Chris Edwards, Graphical Future, 4 ENG'G \& TECH., June 6, 2009, at 36 (describing Nvidia's claim that the GPU's architecture is more efficient in processing data than the CPU architecture, and will eventually replace it)

100 See Nasser Kehtarnavaz \& Mark Gamadia, Real-Time Image and Video ProcessING 40-41 (2006) ("Due to their floating-point calculation capabilities, the increased levels of programmability, and the fact that GPUs can be found in almost every desktop PC today, many researchers have been looking into ways to exploit GPUs for applications other than the realtime rendering of $3 D$ computer graphics, an area of research referred to as general-purpose processing on the graphics processing unit (GPGPU).") (emphasis added); see also Edwards, supra note 99, at 37 (describing the need to educate programmers to write to the GPU's capabilities). 
"GPUs also could facilitate new entry or expansion in the relevant CPU markets by other firms, such as Nvidia, AMD, or Via"101 if OEMs combined their advanced GPUs with cheaper, more rudimentary CPUs. ${ }^{102}$

This story is plausible because the distribution of processing tasks between the CPU and GPU has changed over time. The CPU originally performed the calculations for all of the computer's functions, including graphics. ${ }^{103}$ With the introduction of graphic interfaces like Windows and graphics-intensive applications, ${ }^{104}$ hardware developers moved graphics calculations to a discrete GPU on a separate plug-in card with its own memory and cooling devices. ${ }^{105}$ Microsoft added APIs to Windows to support GPUs. ${ }^{106}$ More recently, Intel and AMD's innovation has moved the graphics processing back to the motherboard in the form of integrated GPUs ${ }^{107}$ and integrated CPU-GPUs. Nvidia's innovation has moved some non-graphics processing onto the GPU through the development of GP-GPUs. Both the CPU and the GPU are thus capable of taking on more or less of the processing functions of the PC, depending upon developers' programming choices and technological changes.

There are limits, however, to the kinds of functionality that the GPU can perform. GPUs are efficient in performing the calculations necessary for massively parallel tasks like complex graphics and certain scientific modeling applications. CPUs, however, are necessary for performing non-computing tasks and for the computations necessary for serial tasks, which are essential in everyday computing. ${ }^{108}$ Thus, while CPUs and GPUs are becoming more fully

\footnotetext{
101 Intel Complaint, supra note 2, 117.

102 One such model of this combination might be Nvidia's Ion motherboard, which pairs a lowend Intel Atom CPU with an Nvidia GeForce $9400 \mathrm{M}$ integrated GPU to produce results that rival those of systems with more advanced CPUs. See Edwards, supra note 99, at 36-38. Another might be the Nvidia's Tegra motherboard for handheld devices, which pairs an ARM processor with an Nvidia GPU. Interestingly, in this device, the GPU takes on functions from the browser, which was the focus of the Microsoft case. Id. at 38.

${ }^{103}$ Even the earliest personal computers required a video card (not, at this stage, a graphics accelerator) to display either text or graphics. In this configuration, the CPU performed all graphics calculations.

${ }^{104}$ Early versions of Windows were slow and prone to freezing because the graphic user interface taxed the CPU, which was already busy doing all the other computing tasks it was designed to perform. Mainly the separate graphics board handles the extraordinary number of calculations necessary to draw graphical interfaces, 3-D games and simulations, and high-end design applications. For example, a few years ago, when one of us (Page) wanted to add a second monitor to his system, and rotate the monitors to a portrait orientation, he discovered that he needed to add more advanced GPU.

${ }^{105}$ A company called S3 sold the first replaceable plug-in graphics accelerator board in 1991.

106 By providing graphics APIs in Windows ("Direct3d" and later "DirectX"), Microsoft sheltered software developers from having to code for every possible dedicated graphics controller.

${ }^{107}$ Integrated GPUs, which are installed as chipsets on the motherboard, are generally less capable of high-end graphics because they share memory with the GPU.

${ }^{108}$ See NCSA (Nat'l Ctr. for Supercomputing Applications), NCSA Answers Questions About GPU Computing (Nov. 3, 2009), http://www.ncsa.illinois.edu/News/Stories/GPUcomputing/.
} 
integrated, GPUs cannot entirely displace CPUs, and it is unclear that advanced GPUs, including GP-GPUs, can be combined with simple CPUs to deliver the same computing power for a normal range of uses. Moreover, for any application to rely on the GPU, it must be reprogrammed at substantial cost. ${ }^{109}$

\section{B. Exclusionary Conduct, Especially Product Design AND INTEROPERATION}

Both Microsoft and Intel involved claims that a platform owner had intentionally limited competition by its product design choices. Microsoft integrated browsing functionality with Windows in ways that provided benefits to users but that also limited the ability of OEMs and end-users to delete that functionality and the code that provided it. The courts considered overlapping aspects of these design changes as tying under Section 1 and monopolization under Section 2. Ultimately, the D.C. Circuit reversed the district court's holding that Microsoft's design choices illegally tied Internet Explorer (IE) to Windows on the ground that the district court should have applied the rule of reason rather than the per se rule, ${ }^{110}$ but it affirmed most of the district court's holdings that Microsoft had monopolized the market for operating systems by many of the same design choices. ${ }^{111}$

The D.C. Circuit's sensitivity to the role of platforms in innovation is most obvious in its consideration of the appropriate tying standard under Section 1 of the Sherman Act. The court concluded that the per se rule was inappropriate to ties involving "technological integration of added functionality into software that serves as a platform for third-party applications" 12 because per se analysis takes account of efficiencies only indirectly by asking whether there is a separate consumer demand for the tied product; if there is no such demand, then there are probably substantial efficiencies associated with selling the tying and tied products together. ${ }^{113}$ But this test, the court observed, is "backward-looking and therefore systematically [a] poor prox[y] for overall efficiency in the presence of new and innovative integration"114 because it condemns a first mover that achieves substantial efficiencies by integrating products consumers still view as distinct. A rule of reason analysis, weighing efficiencies against any restraint in the browser market, was thus necessary to avoid deterring innovation by first movers that decided to combine functional-

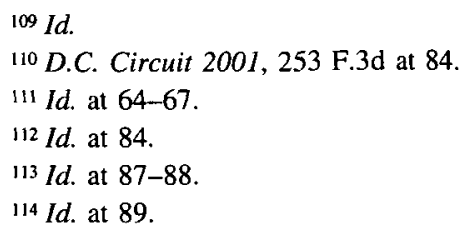


ities. ${ }^{115}$ That analysis was likely to show that tying a browser to the operating system was efficient because OS vendors without market power frequently "incorporate basic internet plumbing and other useful functionality into their OSs." 16 Thus, integrating the functionality of formerly complementary applications into a dominant platform may well be efficient.

The D.C. Circuit's standard of monopolization under Section 2 also considered the special efficiencies of integration in the platform context, but the tone of the discussion was decidedly less deferential to the platform owner's design choices. First, the court of appeals considered whether a practice was anticompetitive, hurting rivals without obviously benefiting consumers; if the practice was prima facie anticompetitive, the defendant could offer an efficiency justification. Applying this standard, the court held that Microsoft did not violate Section 2 "simply by developing an attractive product," 117 even if it was "incompatible with those of its rivals." 118

But the court did condemn design measures that hurt the platform prospects of Netscape's browser without providing benefits to consumers. ${ }^{19}$ The court observed:

As a general rule, courts are properly very skeptical about claims that competition has been harmed by a dominant firm's product design changes. . . . In a competitive market, firms routinely innovate in the hope of appealing to consumers, sometimes in the process making their products incompatible with those of rivals; the imposition of liability when a monopolist does the same thing will inevitably deter a certain amount of innovation. This is all the more true in a market, such as this one, in which the product itself is rapidly changing. . . . Judicial deference to product innovation, however, does not mean that a monopolist's product design decisions are per se lawful. ${ }^{120}$

The court held that three of Microsoft's design changes reduced competition by hindering the platform threat posed by Netscape's browser, and that two of these changes lacked an efficiency justification. Excluding Internet Explorer from the Add/Remove Programs utility made it harder for OEMs to delete the

\footnotetext{
$115 \mathrm{Id}$. at 92.

${ }^{116} \mathrm{Id}$. at 93 . The government understandably declined to pursue this claim on remand because it would have been required to prove that the tie reduced competition in the market for browsers, which the court had already held did not exist.

117 Id. at 68 (considering Microsoft's development of a free Internet Explorer Access Kit for Internet Access Providers).

${ }^{118}$ D.C. Circuit 2001, 253 F.3d at 74-75 (considering Microsoft's Windows-specific version of Sun's Java Virtual Machine).

${ }^{119}$ Id. at 64-65 (considering "excluding IE from the 'Add/Remove Programs' utility; designing Windows so as in certain circumstances to override the user's choice of a default browser other than IE; and commingling code related to browsing and other code in the same files, so that any attempt to delete the files containing IE would, at the same time, cripple the operating system").

${ }^{120}$ D.C. Circuit 2001, 253 F.3d at 65.
} 
visible means of access to IE. Similarly, commingling "code specific to Web browsing in the same files as code that provided operating system functions" deterred OEMs from deleting browser code because doing so "would also delete vital operating system routines and thus cripple Windows." 121 Both of these design choices made it less attractive for OEMs to pre-install Netscape's browser alone ${ }^{122}$ and thus increased Microsoft browser usage share "through something other than competition on the merits." 123

Microsoft failed to substantiate its claim that the efficiency benefits of integration justified these choices. ${ }^{124}$ Designing Windows to launch Internet Explorer for certain tasks and in certain contexts regardless of the user's choice of a default browser was also anticompetitive because it "prevent[ed] some people from using other browsers," 125 but Microsoft justified the overrides by pointing out that Netscape's browser could not perform the relevant tasks at all or as well. ${ }^{126}$ Although seemingly tangential, the court's holding on the default override all but foreclosed any future remedy that required the removal of browsing code because all of the code was necessary for IE to function in the instances in which the override was justified.

In Intel, the FTC alleged that Intel reduced competition in both the CPU and GPU markets as they are presently structured. ${ }^{127}$ But it also alleged a scenario, similar to the central narrative in Microsoft, in which Intel reduced future competition on both price and innovation between its CPUs and its rivals' GPUs or GP-GPUs. ${ }^{128}$ In this scenario, as in Microsoft, the actions of rivals threatened to commoditize the defendant's platform product by innova-

$$
\begin{aligned}
& 121 \mathrm{Id} \text {. at } 65-66 . \\
& { }^{122} \mathrm{Id} \text {. at } 65 . \\
& { }^{123} \mathrm{Id} \text {. } \\
& { }^{124} \mathrm{Id} \text {. at } 66-67 .
\end{aligned}
$$

$125 \mathrm{Id}$. at 65 . At the time, Windows would launch IE to access Windows Help and Windows Update sites and whenever the user accessed the Internet through "My Computer" or "Windows Explorer."

126 Id. at 67 . The Netscape browser did not support the Active X controls on which Windows Help and Windows Update depend, and did not allow users to access the Internet within the My Computer or Windows Explorer windows.

127 The FTC also alleged that "Intel redesigned its compiler and library software in or about 2003 " in ways that had "no legitimate technical benefit," and whose only purpose was "to reduce the [apparent] performance of competing CPUs relative to Intel's CPUs." It did this by designing the compilers to translate applications programs into object code that ran slower on AMD's CPU's than on Intel's - thus creating the impression that AMD's processors were slower. Intel Complaint, supra note 2, II 8. The FTC also alleges that Intel bundled its CPU with its chipset with integrated graphics, but this action is challenged only on the basis of pricing. Id. I 24

${ }^{128}$ Id. II 27. ("The loss of price and innovation competition in the relevant markets will continue to have an adverse effect on competition and hence consumers. Absent the remedy provided herein, Intel will continue to maintain or even enhance its market power, consumers will have fewer choices, prices will be higher than they would be in competitive markets, and quality and innovation will be diminished."). 
tions that could shift the key functionality of the platform to a complement, and the defendant responded by trying to slow the development and adoption of rival technologies. ${ }^{129}$

After having cooperated with GPU producers like Nvidia and having encouraged them to develop interoperable products using the interfaces that Intel supported, ${ }^{130}$ Intel allegedly limited interoperability when their innovative efforts threatened its dominance. For example, it "reversed its previous course of allowing Nvidia's integrated GPU chipsets to interoperate with Intel CPUs, thereby foreclosing Nvidia's integrated GPU chipsets from connecting to Intel's future CPU platforms." 131 It allegedly took similar steps to impede interoperability for discrete GPUs ${ }^{132}$ as a way of limiting GP-GPU computing functionality. Intel allegedly did all this to thwart the prospect that the GPU would "emerge as a potential challenge to Intel's monopoly over CPUs." 133 Because of Intel's history of dealing with complementors, the FTC asserted (implicitly invoking Aspen Skiing) ${ }^{134}$ that Intel had a duty to assure that complementors' products would "interoperate freely, fully, and in a nondiscriminatory manner with its CPUs, chipsets, and related connections." 135

According to the FTC, the GPU producers are thus nascent platform rivals of Intel in CPU and GPU markets at least as clearly as Netscape or Java were nascent rivals of Microsoft in an undefined platform market that included both operating systems and middleware. ${ }^{136}$ Moreover, the FTC alleged that Intel illegally denied interoperability to its nascent rivals just as the DOJ alleged Microsoft had denied interoperation to Java by developing an incompatible

${ }^{129}$ Id. II 19 ("These measures are intended to slow down developments in the relevant markets until Intel can catch up, and have had the effect of foreclosing competitive GPU products and slowing the development and widespread adoption of GP GPU computing.").

130 "Intel encouraged Nvidia to innovate on the Intel platform. Intel and Nvidia worked together for a number of years to ensure that Nvidia's GPUs could interoperate with Intel's CPU." Id. II 82. "Intel licensed Nvidia to allow it to manufacture GPUs integrated on chipsets to be used with Intel's CPUs." Id. If 83. "Intel engaged in deception by misleading Nvidia on Intel's CPU roadmaps, thereby greatly increasing its competitor's costs and further delaying the development of other products that would have accelerated the adoption of GP GPU computing." Id. II 85.

131 Id. 9184.

132 "For discrete GPUs, Intel has created several interoperability problems, including reductions of speed and encryption, that have had the effect of degrading the industry standard interconnection with Intel's CPUs." Id. II 86.

133 Id. 1123.

${ }^{134}$ Aspen Skiing Co. v. Aspen Highlands Skiing Corp., 472 U.S. 585, 603 (1985) (the right to refuse to deal was qualified where "the monopolist did not merely reject a novel offer to participate in a cooperative venture that had been proposed by a competitor [but] elected to make an important change in a pattern of distribution that had originated in a competitive market and had persisted for several years").

135 Id.

136 PAGE \& LOPATKA, supra note 1, at 105-06 (middleware and operating systems were only competitors in an undefined "market in which platform producers compete for the attention of developers by adding APIs"). 
Java Virtual Machine. But, as the Microsoft court eventually determined, denials of interoperability are monopolistic only if they actually reduce competition and lack efficiency justifications. ${ }^{137}$ The increasing integration of CPUs and GPUs could provide such a justification if the most efficient design requires limiting interoperation with discrete GPUs. Not only Intel but AMD, which lacks monopoly power, is pursuing the path of integration. As a result, Nvidia has reportedly been forced to limit its development program for integrated GPUs. ${ }^{138}$ For reasons we described in the last section, the FTC's predictions that the GPU will evolve to displace more capable CPUs are questionable. To the extent the FTC exaggerated the interchangeability of functions between the CPU and GPU, its account of Intel's motive for hindering interoperability between the CPU and GPU and its prediction of their likely effects become correspondingly less plausible.

\section{Remedies}

Much of the significance of a finding of liability (or a settlement) turns on the specifics of the ensuing remedy. In both Microsoft and Intel, the special role of platforms in innovation was a pervasive concern in shaping relief. For example, the court of appeals in Microsoft reversed the district court's initial order that would have broken Microsoft up, because it failed to address Microsoft's contention that such an order would "lower[ ] rates of innovation and disrupt[] the evolution of Windows as a software development platform." 139 The district court's later decision approving the terms of the settlement in the case (and imposing the same terms in a separate case pursued by nonsettling state plaintiffs) was also cautious about intruding on Microsoft's design choices. It recognized that remedies should stop proven anticompetitive conduct, but scrutinized any claim that relief should go further by changing industry structure, mandating disclosures of trade secrets, or regulating product design and commercial relationships. The FTC in Intel was similarly at some pains to explain how the relief in its consent order promoted innovation by Intel's rivals without inhibiting legitimate innovation by Intel itself.

\footnotetext{
${ }^{137}$ See supra Part I.B.1. In order to violate the antitrust laws, the incompatible product must have an anticompetitive effect that outweighs any procompetitive justification for the design. D.C. Circuit 2001, 253 F.3d at 75 (reversing a finding of liability for developing a Windowsspecific Java Virtual Machine because the new product "allow[ed] applications to run more swiftly and [did] not itself have any anticompetitive effect").

138 Jon Stokes, Day of Chipset Reckoning Arrives for Nvidia, Ars TeChNica (Oct. 8, 2009), http://arstechnica.com/hardware/news/2009/10/day-of-nvidia-chipset-reckoning-arrives.ars; see also Jon Stokes, Latest GPU Market Numbers Spell Bad News for Nvidia, ARs TeCHNICA (May 3, 2011), http://arstechnica.com/business/news/2011/05/latest-gpu-market-numbers-spell-badnews-for-nvidia.ars.
}

${ }^{139}$ D.C. Circuit 2001, 253 F.3d at 102. 
We will focus on the two remedies' treatment of product design and interoperability. The court of appeals in Microsoft held two types of product design anticompetitive and unjustified: the failure to provide a means of deleting the visible means of accessing the browser, and the commingling of browser and operating system code. Both were found anticompetitive for the same reason-they deterred OEMs and end-users from removing IE and thus deterred them from installing Netscape's browser in its place. At the remedial stage, however, the approved relief ${ }^{140}$ included no remedy specifically aimed at commingling code; it required instead that Microsoft assure that OEMs and end-users could make unbiased choices of rival middleware. ${ }^{141}$ For example, it required Microsoft to provide ways to delete the means of access to the defined middleware, by icons, menu items, and so forth. ${ }^{142}$ Microsoft complied with this provision by creating (and modifying in response to the plaintiff's concerns) a utility that would allow OEMs and end-users to set which programs would be accessible and which would be the default program for that function. ${ }^{143}$ Implementation of the "competing middleware and defaults" provisions involved detailed supervision of the design of portions of several versions of Windows, but Microsoft was able to comply with the plaintiffs' requirements without major delays.

The courts rejected arguments by the nonsettling states that the remedy should require Microsoft to allow removal of the actual code that provides the middleware's functionality. Such a remedy, they reasoned, would come at great cost and provide no greater benefit than the decree's requirement that Microsoft allow removal of visible means of access to the functionality. One of the primary costs of such a remedy would be that developers could no longer assume that the standard Windows API was intact. The district court, for example, found that "Microsoft's innovation would be stifled by the re-

\footnotetext{
${ }^{140}$ Second Modified Final Judgment, United States v. Microsoft Corp., No. 98-1232, 2009 WL 1348218 (D.D.C. Apr. 22, 2009) [hereinafter Microsoft Judgment]. This modified version of the consent decree supersedes earlier versions entered November 12, 2002 and September 7, 2006. All of our remaining citations will be to this most recent version. There were actually two Final Judgments in Microsoft because the so-called nonsettling or "California Group" of states declined to participate in the settlement of the federal case, but the differences between the two judgments are minor and do not affect our analysis here. For much more discussion of remedies in the case, see William H. Page \& Seldon J. Childers, Measuring Compliance with Compulsory Licensing Remedies in the American Microsoft Case, 76 AnTiTRust L.J. 239 (2009) [hereinafter Measuring Compliance]; William H. Page \& Seldon J. Childers, Software Development as an Antitrust Remedy: Lessons from the Enforcement of the Microsoft Communications Protocol Licensing Requirement, 14 Mich. Telecomm. \& Tech. L. Rev. 77 (2007) [hereinafter Software Development].

141 Microsoft Judgment, supra note 140, §§ III.C \& III.H.

${ }^{142}$ Id. § III.H.1. The mechanisms must provide separate and unbiased choices in these actions.

${ }^{143}$ Joint Status Report on Microsoft's Compliance with the Final Judgments at 9-12, United States v. Microsoft Corp., No. 98-1232 (D.D.C. filed Oct. 19, 2005), available at http:// www.justice.gov/atr/cases/f212100/212195.htm.
} 
quirement that it redesign its products, [and] the ability of ISVs to innovate would be slowed because of the detrimental effects of the presence in the marketplace of multiple versions of Microsoft's Windows operating system, each with different code and different APIs."144 The court of appeals added that the decree's approach was sufficient in "reducing the costs an OEM might face in having to support multiple internet browsers," thus hindering "Microsoft's efforts to reduce software developers' interest in writing to the [APIs] exposed by any operating system other than Windows," all "without intruding itself into the design and engineering of the Windows operating system." 145 The court of appeals also agreed that there was value in not fragmenting the Windows API and thus reducing innovation by Microsoft's ISVs: "addressing the applications barrier to entry in a manner likely to harm consumers is not self-evidently an appropriate way to remedy an antitrust violation." 146

The court of appeals also agreed with the district court that no specific remedy was necessary for the "Java deception" episode. The court had rejected the district court's holding that Microsoft monopolized by developing a Windows-specific JVM, because that product was faster than Sun's crossplatform version. But the court upheld the holding that Microsoft monopolized by representing to developers that its JVM was cross-platform (i.e., not Windows-specific). In other words, the design itself was lawful but Microsoft's deceptive marketing of the design was not. In the remedies proceedings, the court of appeals rejected the suggestion that the Java deception justified an order requiring Microsoft to continue to support any industry standard that it claimed to support or that it had altered by making proprietary extensions. ${ }^{147}$ It was not enough to point to expert testimony that "Microsoft's proprietary control over 'important interfaces' would make it 'harder' for rival operating systems to compete with Windows," because full compliance with industry standards was subjective, difficult, and in some instances impossible. ${ }^{148}$

Thus, the court refused to order costly and unnecessary product design changes and interoperability measures as relief for some of the conduct that it had found unlawful. On the other hand, the consent decree imposed remedies for some conduct that was never found illegal. During the negotiations over the remedy, the government raised the long-standing (but never substantiated) concerns that Microsoft manipulated its APIs to hinder interoperability with

\footnotetext{
144 D.D.C. States Remedy 2002, 224 F. Supp. 2d at 158.

${ }^{145}$ D.C. Circuit 2004, 373 F.3d at 1210.

$146 \mathrm{Id}$. at 1211 .

${ }^{147} \mathrm{Id}$. at 1215 .

${ }^{148} \mathrm{Id}$.
} 
certain third-party applications in order to favor its own applications. ${ }^{149}$ Microsoft agreed to a remedy that required it to document its APIs ${ }^{150}$ as well as "native" communication protocols that its server operating systems use to interoperate with Windows clients. ${ }^{151}$ The district court approved the provisions enthusiastically, identifying the protocol-licensing provision as "the most forward-looking" relief in the decree because it would facilitate innovation in network computing. ${ }^{152}$ The court of appeals agreed, with some reservations. ${ }^{153}$

Its reservations were justified. The API provision caused few major problems, but the protocol-licensing requirement proved to be so costly and difficult to satisfy that the district court felt compelled to extend the term of the final judgment until May 12, 2011.154 Microsoft was able to satisfy the government that it had complied with this portion of the final judgments after almost a decade of effort, including testing under the supervision of a Technical Committee of experts. ${ }^{155}$ Even with the enormous efforts to document and make available the covered protocols, the provision had little, if any, measurable effect on competition. ${ }^{156}$ Given these meager benefits, we can see in retrospect that this provision was the most misguided and costly aspect of the government case.

The consent order in Intel also addresses issues of product design and interoperability. Unlike Microsoft, the FTC in Intel alleged a number of actual denials of interoperation with rivals in CPU, GPU, and GP-GPU computing, which we summarized in the last section. ${ }^{157}$ The proposed order addresses these concerns in two primary ways: mandating that Intel support a standard interface to promote interoperability ${ }^{158}$ and prohibiting "predatory design" or

\footnotetext{
149 Page \& Childers, Software Development, supra note 139, at 93-102.

${ }^{150}$ Microsoft Judgment, supra note 140, § III.D.

151 Id. $\S$ III.E.

152 D.D.C. States Remedy 2002, 224 F. Supp. 2d at 173.

153 D.C. Circuit 2004, 373 F.3d at 1222-25.

154 New York v. Microsoft Corp., 531 F. Supp. 2d 141, 144 (D.D.C. 2008) (D.D.C. Extension 2008).

155 Joint Status Report on Microsoft's Compliance with the Final Judgments at 4, United States v. Microsoft Corp., No. 98-1232 (D.D.C. filed Apr. 22, 2011), available at http:// www.justice.gov/atr/cases/f270200/270210.pdf ("Plaintiffs' overall assessment is that the documents are of sufficient completeness and quality such that the Communications Protocols, as defined in the Final Judgments, are 'available for use by third parties' within the meaning of Section III.E."). Microsoft indicated that it would continue these interoperability efforts after the decrees expired. $I d$. at 9.

156 Page \& Childers, Measuring Compliance, supra note 139, at 266-69.

157 See supra text accompanying notes 127-31.

158 Intel Order, supra note $2, \S$ II.
} 
"predatory innovation"159 that hinders interoperability. ${ }^{160}$ The required interface is some version of the PCI Express bus. GPUs communicate with the CPU using the PCI Express bus under the PCIe standard. In desktop computers, a discrete GPU board typically plugs into a PCIe expansion slot; integrated GPUs also communicate with the CPU using a PCle interface, but one that is a component of the motherboard.

The order requires Intel to maintain the PCIe interface for up to six years and not to take any actions that would degrade its functionality as an interface. ${ }^{161}$ Relatedly, Intel must, annually through 2015 , provide Nvidia with roadmaps disclosing how its processor platforms will implement the PCIe interface. ${ }^{162}$ By keeping the PCIe bus available as long as it remains an industry standard, and agreeing not to alter it to limit interoperability, Intel assures its complementors that "they will be able to connect to Intel CPUs in both mainstream and high-performance computers in the future" and "that their products will remain viable and thus maintain their incentives to innovate--including the continued development of alternative computing architectures such as General Purpose GPU computing." 163 The provision is designed to allow standalone GPU makers, particularly Nvidia, to compete for inclusion in Intel systems that have integrated Intel GPUs. The FTC evidently was concerned that Intel would abandon PCI Express in favor of other interfaces that would disadvantage Nvidia.

The order also prohibits Intel from engaging in "predatory design"-making any design change (other than an inadvertent bug) that "degrades the performance" of rival products without "provid[ing] an actual benefit" to Intel's product. ${ }^{164}$ The FTC explains that this provision bars design measures that "solely disadvantage competitive or complementary products" by, for exam-

\footnotetext{
159 Analysis of Consent Order, supra note 9, at 13.

160 Intel Order, supra note $2, \S \mathrm{V}$.
}

${ }^{161} \mathrm{Id}$. $\S$ Il.C. On November 2, 2010, the FTC modified its order to allow Intel to sell until 2013 a chip code-named Oak Trail that had been in development before the effective date of the decree, even though it does "not include the Required Interface in [the] Mainstream Microprocessor Platform." See id. § II.E.

162 Id. $\S$ VI.B. The required roadmap is defined as one "that identifies the internal development name of future Mainstream Microprocessors under development by Respondent and, for each, the calendar quarter within which such product is then-planned to be commercially introduced and the then-planned version of the Standard PCI Express Bus interface." Id. $\S$ I.DD.

${ }^{163}$ Analysis of Consent Order, supra note 9, at 7.

164 Intel Order, supra note 2, § V.A. This standard resembles the "sham test" described in Richard Gilbert, Holding Innovation to an Antitrust Standard, COMPETITION POL'y INT'L, Spring 2007, at 47,61-62. Gilbert argues that antitrust should give "if not a safe harbor, at least a wide berth for innovation by a single firm, because innovation nearly always increases economic welfare and the adverse effects of innovation that excludes rivals are typically no greater than the effects of a unilateral refusal to deal." 
ple, "cutting off competitors' access to its CPUs and slowing down various connections to the CPU."165

Despite the FTC's characterization of the conduct as "predatory," the harm from the design change need not be intentional. Moreover, Intel bears the burden of proving a "real" benefit in order to avoid liability. On the other hand, the provision does not "require a balancing test that would weigh the anticompetitive harms against the benefits of a particular Intel design change; it is sufficient that there be actual benefits."166 Interestingly, the FTC suggests that a "balancing test would be appropriate in a legal challenge to an Intel design change under Section 5 of the FTC Act or Section 2 of the Sherman Act," but that would require a separate lawsuit. ${ }^{167}$

Neither of these proposed requirements violates the lessons of the Microsoft experience. At first glance, the mandate to support the PCIe standard bus seems to contradict the finding in Microsoft that a mandate to support industry standards was likely to be difficult and counterproductive. But the court in Microsoft was addressing a proposal that Microsoft maintain compliance with an open-ended class of standards that "var[ied] widely in complexity and specificity" and for which there were incompatible implementations. The PCle mandate is far narrower. The PCIe mandate also might raise concerns that complying with the standard will involve the parties in a costly and futile compliance program like the one implementing the Microsoft protocol-licensing provision. But the protocol-licensing provision required Microsoft to identify and document scores of protocols that Microsoft had never documented even internally and to provide extensive technical support to developers that might want to use the protocols. The requirement that Intel support the PCIe standard, by contrast, is focused on a standard interface that Intel has supported for years. Continuing that support should be straightforward and easily supervised.

By its terms, the order allows Intel to "determine the version or specification of the Standard PCI Express Bus interface (e.g., PCle Base Specification 2.1, PCle Base Specification 3.0) that will be included in each of its Main-

\footnotetext{
165 Analysis of Consent Order, supra note 9, at 13.

$166 \mathrm{Id}$.

${ }^{167} \mathrm{Id}$. The court of appeals in Microsoft also held that "if the monopolist's procompetitive justification stands unrebutted, then the plaintiff must demonstrate that the anticompetitive harm of the conduct outweighs the procompetitive benefit." D.C. Circuit 2001, 253 F.3d at 59. The court never reached this stage of the test, however. In the court's analysis, product design changes that brought obvious benefits were not anticompetitive at all. But $c f$. Jean Tirole, The Analysis of Tying Cases: A Primer, COMPETITION POL'Y INT'L, Spring 2005, at 1, 20-21 (arguing that "predation does not always imply a cost for the predator; yet, the efficiency gains may be more than offset by the increase in future monopoly power from a social perspective").
} 
stream Microprocessor Platforms subject to this provision." 168 The cost of supporting the PCIe standard is likely to decrease year-by-year due to the normal price behavior of aging technologies. Moreover, it will not prevent Intel from introducing a newer, improved standard, because both standards can be simultaneously supported. For example, for a number of years, Intel-compatible motherboards featured both AGP (a prior bus standard) as well as PCIe board slots.

Via objected that the order should

require full and open interoperability. It should require that Intel publish enough information for other companies to be instruction-set, bus, and pin compatible with Intel's CPUs. Intel should be prohibited from asserting intellectual property rights over this information when used to connect peripherals to an Intel CPU and should be required to offer FRAND [fair, reasonable, and non-discriminatory] terms to connect competing CPUs to peripherals designed for Intel CPUs (with a royalty based only on the actual incremental benefit of any new protocol relative to other existing options). ${ }^{169}$

Such an order would have been closer to the communications protocol program, and would have raised similar problems of compliance. The FTC responded after the close of the comment period:

Your suggestions entail Intel disclosing significant design information about its CPUs and bus protocols and forgoing enforcement of any patents that are connected to implementation of those technologies; essentially, your proposal would allow Intel's competitors to copy of [sic] Intel products without fairly compensating Intel. Such a requirement would strip Intel and its competitors of incentives to innovate. ${ }^{170}$

This response reflects appropriate awareness of the costs of excessive disclosure and interoperability measures in antitrust cases.

The predatory innovation provision is also less problematic than its name might otherwise suggest. It does not broadly protect rivals from innovation by a dominant firm. Instead, it imposes a duty similar to the D.C. Circuit's monopolization standard in Microsoft: a design measure may be unlawfully exclusionary if it harms a nascent rival without providing consumer benefits. In some of Microsoft's innovations, like the Windows-specific JVM, the benefits were sufficiently obvious from test results that no further inquiry was necessary; if they were less obvious, then Microsoft was required to offer an effi-

168 Intel Order, supra note 2, § II.B. Via objected that this provision "allows Intel to implement an already obsolete version of PCI Express, maintaining its proprietary DMI Protocol as the "must have' connection." Comment of Via Technologies, Inc. at 7, Intel Corp., FTC Docket No. 9341 (Aug. 31, 2010) [hereinafter Via Comment], available at http://www.ftc.gov/os/comments/ intelcorp/550006-00012-55265.pdf.

169 Via Comment, supra note 167 , at 8.

${ }^{170}$ Letter to Via Technologies, Inc., at III, Intel Corp., FTC Docket No. 9341 (Oct. 29, 2010), available at http://www.ftc.gov/os/adjpro/d9341/101102intelletterchen.pdf. 
ciency justification, as it was able to do in the case of the default overrides. It seems unlikely that Intel, whose business model depends on coordination of its platform design with complementors, will have difficulty showing the benefits of its design choices.

One measure of the costs of implementing an antitrust remedy in high technology is the role of technical consultants. In Microsoft, the consent decree authorized the creation, at Microsoft's expense, of a Technical Committee (TC) of software design experts to track Microsoft's compliance with the decree on behalf of the plaintiffs. ${ }^{171}$ The nonsettling states hired a technical consultant, also at Microsoft's expense, who worked essentially as part of the TC. ${ }^{172}$ The TC and its staff of engineers worked for over seven years on many tasks, especially testing Microsoft's documentation of its protocols. The cost of operating the TC, including salaries, travel, equipment, among other things, is not publicly known, but it must run to many millions of dollars; Microsoft's internal costs of compliance must be a multiple of that. In contrast, the Intel consent decree authorizes the FTC to appoint technical consultants at Intel's expense only if reasonably necessary and with an overall cap of $\$ 2$ million in payments to the consultants. ${ }^{173}$ This nominal cap suggests that the parties do not anticipate and will not incur the sort of expenses that the TC and Microsoft likely faced in the implementation of the protocol licensing provision of its consent decree.

\section{CONCLUSION}

The FTC's disposition of Intel suggests that the antitrust community has learned the lessons of the Microsoft case. Platform markets and the platform owners have central roles in innovation in our must innovative markets, yet they are also in a position to skew innovation in ways that may be inconsistent with consumer welfare. We have considered how these characteristics should influence the interpretation of antitrust standards, and then compared how the courts in Microsoft and the FTC in Intel actually implemented antitrust standards on the issues of market definition, liability, and remedies. Where Microsoft properly recognized the competing considerations, the FTC followed its lead. Equally important, the FTC recognized those measures in the Microsoft final judgments that subsequent experience showed were unduly costly, and agreed to terms that avoided similar pitfalls.

\footnotetext{
171 Microsoft Judgment, supra note 140, $\S$ IV.B.2 \& IV.B.8.

172 D.D.C. Extension 2008, 531 F. Supp. $2 d$ at 157 n.25.

${ }^{173}$ Intel Order, supra note 2, § IX A. \& B.
} 
